\title{
Neocrangon orientalis, a new caridean shrimp species (Crustacea, Decapoda, Crangonidae) from the East China Sea
}

\author{
QINGXI HAN ${ }^{1,2}$ \& XINZHENG LI ${ }^{1,3}$ \\ ${ }^{1}$ Institute of Oceanology, Chinese Academy of Sciences, 7 Nanhai Road, Qingdao 266071, China \\ ${ }^{2}$ Graduate University, Chinese Academy of Sciences, Beijing 100049, China \\ ${ }^{3}$ Corresponding author. E-mail: lixzh@ms.qdio.ac.cn
}

The Genus Neocrangon Zarenkov, 1965 was one of the most poorly reported genera in the caridean family Crangonidae. Zarenkov (1965) divided the genus Crangon Fabricius, 1758 into two subgenera, ie. Crangon s. str. and his new subgenus Neocrangon, and designed eleven species in the latter, the type species was Crangon communis Rathbun, 1899. Squires and Figueira (1974) followed Zarenkov (1965) and accepted the subgenus Neocrangon. Kuris \& Carlton (1977) raised Neocrangon as a separated genus and recognized that only five species, which has two gastric spines as that in the type species from the eleven species designed by Zarenkov (1965), belonging to Neocrangon. The five species were: Neocrangon communis (Rathbun, 1899), N. abyssorum (Rathbun, 1902), N. resima (Rathbun, 1902), N. joloensis (De Man, 1929) and $N$. zacae Chace, 1937. Then, Wicksten (1996) synonymized $N$. zacae Chace, 1937 as a junior synonym of N. resima (Rathbun, 1902). Up to date, four species have been recognized in the genus Neocrangon Zarenkov, 1965.

When we sorted the crangonid shrimp specimens deposited in the collections of the Institute of Oceanology, Chinese Academy of Sciences, Qingdao (IOCAS), eight specimens belonging to Neocrangon collected by trawling in the ChinaAmerica Continental Shelf Cooperative Investigation of the East China Sea (1978-1979) were separated out and were identified belonging to an undescribed species. Based on the specimens, we describe a new species in the present paper. The following abbreviations are used in the text: cl, postorbital carapace length; $\mathrm{CN}$, collection number, referring to the preliminary registration number when the specimen(s) was collected; MBM, Marine Biological Museum of the IOCAS.

\section{Neocrangon orientalis sp. nov.}

(Figs 1-2)

Material examined. East China Sea. MBM228966, holotype, female (cl 7.71 mm), CN V580B-50, 30³1.0'N, $127^{\circ} 56.5^{\prime} \mathrm{E}$, 365-395 m, muddy sand, Agassiz trawl, collectors: ZC Tang \& JS Xu, 1 Jul 1978; MBM228967, paratypes, 2 females (cl 7.09, $8.85 \mathrm{~mm}$ ), same data as holotype; MBM228968, paratypes, 1 male (posterior carapace and proximal pleon damaged), 4 females (cl 7.88-9.81 mm), CN V580B-55, same data as holotype.

Dignosis. Eyes moderate in size. Rostrum compressed laterally, slightly up-curved, tapered, dorsal carina faint, distinctly exceeding beyond end of cornea. Antennal scale about 0.94 (0.89-0.96) times of carapace length, about 4.13 (3.98-4.27) times longer than broad. Area among antennal, branchiostegal and hepatic spines deeply depressed, with grooves. First five pleomeres smooth, without dorsal carina, pleuron of fifth pleomere with posterolateral spine, sixth pleomere bearing pair of submedian carinae separated by median sulcus.

Description. Body slender, slightly compressed laterally. Integument very thin, with sparse long setae.

Eyes kidney-like, moderate in size (Fig. 2A). Corneal width about $0.27(0.25-0.29)$ times of carapace length.

Rostrum (Fig. 2A) compressed laterally, slightly up-curved, tapered, about 0.38 (0.36-0.41) times of carapace length, distinctly exceeding beyond end of cornea. Anterodorsal tip acute. Dorsal carina of rostrum faint.

Carapace (Fig. 1) about 1.24 (1.18-1.28) times longer than wide. Dorsal surface armed with two teeth, posterior one stronger and larger, at about midlength of carapace, continued posteriorly with carina extending 0.6 of distance between posterior tooth and posterior margin of carapace, anterior dorsal tooth minute, nearly at level of posterior orbital margin, continued with an unconspicuous carina. Dorsolateral surface with unconspicuous carina paralleled with dorsal carina. Sulcus started from hepatic groove extending posteriorly beyond level of posterior dorsal tooth. Orbital, antennal, branchiostegal and pterygostomian spines present. Orbital spine larger than antennal spine, almost same as hepatic spine 
in size, continued posteriorly with short ridge; antennal spine acute, continued posteriorly with deep groove, combined with hepatic groove at posterior end; branchiostegal spine large, continued posterodorsally with low carina extending to basis of hepatic spine; pterygostomian spine minute. Orbital margin with deep, distinct cleft. Area among antennal, branchiostegal and hepatic spines deeply depressed, with grooves.

Fifth to eighth thoracic sternites armed with high, distinct plate respectively, anteriorly protruded into large spine, plates of fifth and sixth thoracic sternites located closely.

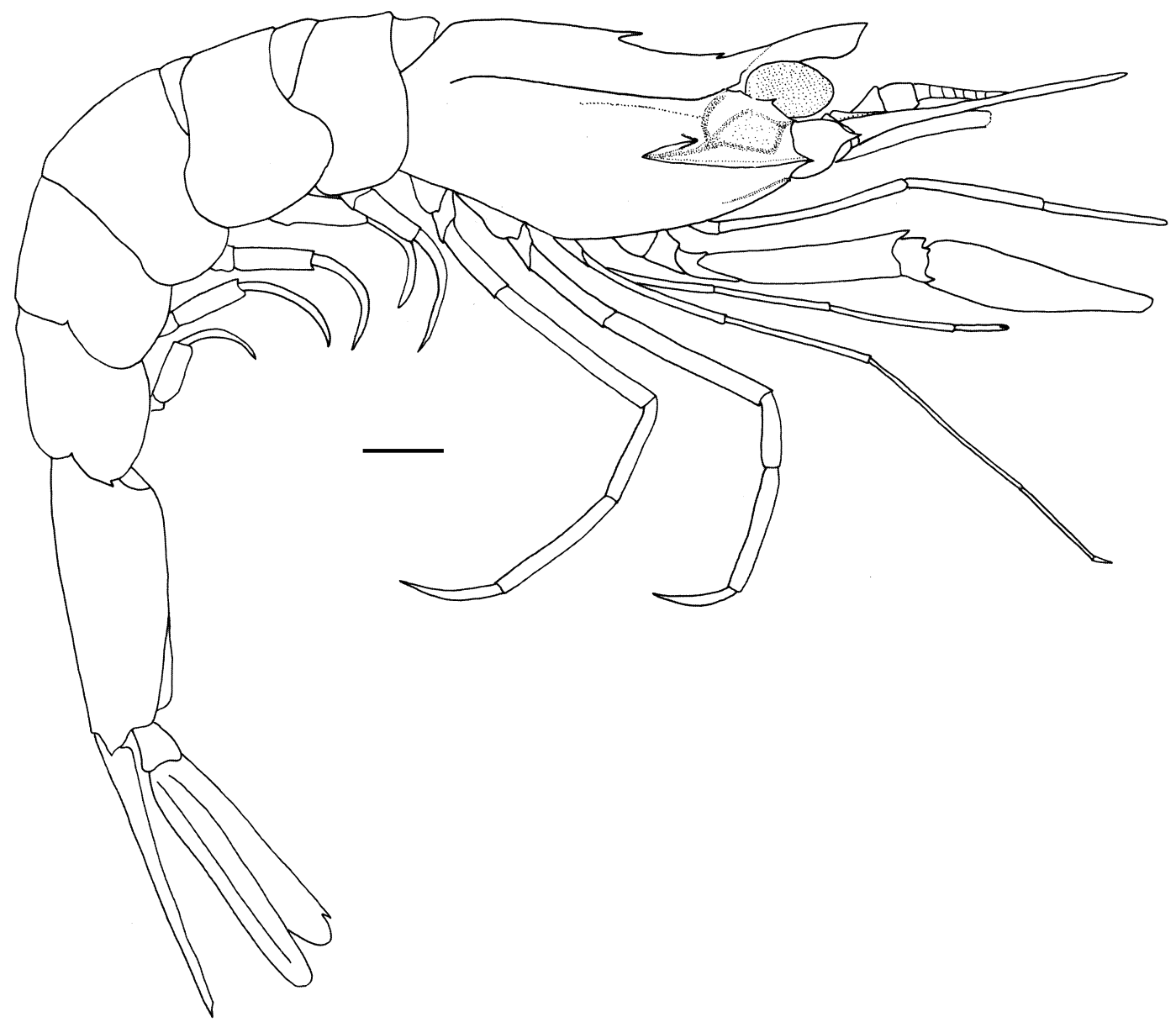

FIGURE 1. Neocrangon orientalis sp. nov. Holotype female (cl $7.71 \mathrm{~mm})$, MBM228966, lateral view. Scale bar: $1 \mathrm{~mm}$.

Anterior five pleomeres smooth, without dorsal carina. Pleura of pleomeres ventrally broad rounded, fifth pleomere armed with posterolateral spine. Sixth pleomere about 0.87 (0.85-0.89) times of carapace length, bearing pair of submedian carinae separated by median sulcus (Fig. 2B). Sternites of anterior four pleomeres armed with large, acute median spines, sixth pleomere elevated into high blunt tubercle. Telson tapered posteriorly, with median longitudinal groove extending almost whole telsonal length, with four pairs of dorsolateral spines, anterior pair at midlength of telson, posterior pair at about posterior 0.25 of telsonal length, tip of telson armed with two pairs of long setae.

Antennal scale about 0.94 (0.89-0.96) times of carapace length, about 4.13 (3.98-4.27) times longer than wide, distolateral spine far exceeding distal margin of lamella.

Third maxilliped overreaching distal margin of lamella of antennal scale with ultimate segment. First pereiopod robust, exceeding antennal scale with dactylus; merus armed with strong spine on distal end of dorsal surface and two small spines respectively on outer and inner distal margins of ventral surface (Fig. 2C, D). Second pereiopod slender, dactylus about 0.2 of palmar length (Fig. 2E, F); Third pereiopod very slender, overreaching distal margin of lamella of antennal scale with dactylus and distal 0.67 of propodus (Fig. 2G). Fourth and fifth pereiopods with dactyli curved ventrally (Fig. 2H, I); Second, fourth, fifth pereiopods failing to reach distal margin of lamella of antennal scale.

Uropods overreaching telson (Fig. 2B).

Coloration in life. Unknown.

Size. All females non-ovigerous, 7.09-9.81 mm in cl; male unknown.

Variations. One paratype female (MBM228968, cl $8.06 \mathrm{~mm}$ ) has its rostrum strongly ascended as much as $45^{\circ}$; one 
paratype female (MBM228967, cl 7.09) and two paratype females (MBM228968, cl 8.06, 8.07 mm) have a small and inconspicuous tubercle posterior to the anterior dorsal spine.

Distribution. So far only known from the type locality in the East China Sea, at the depths of 365-395 meters.

Etymology. Drived from the Latin orientalis, referring to the type locality of the new species.

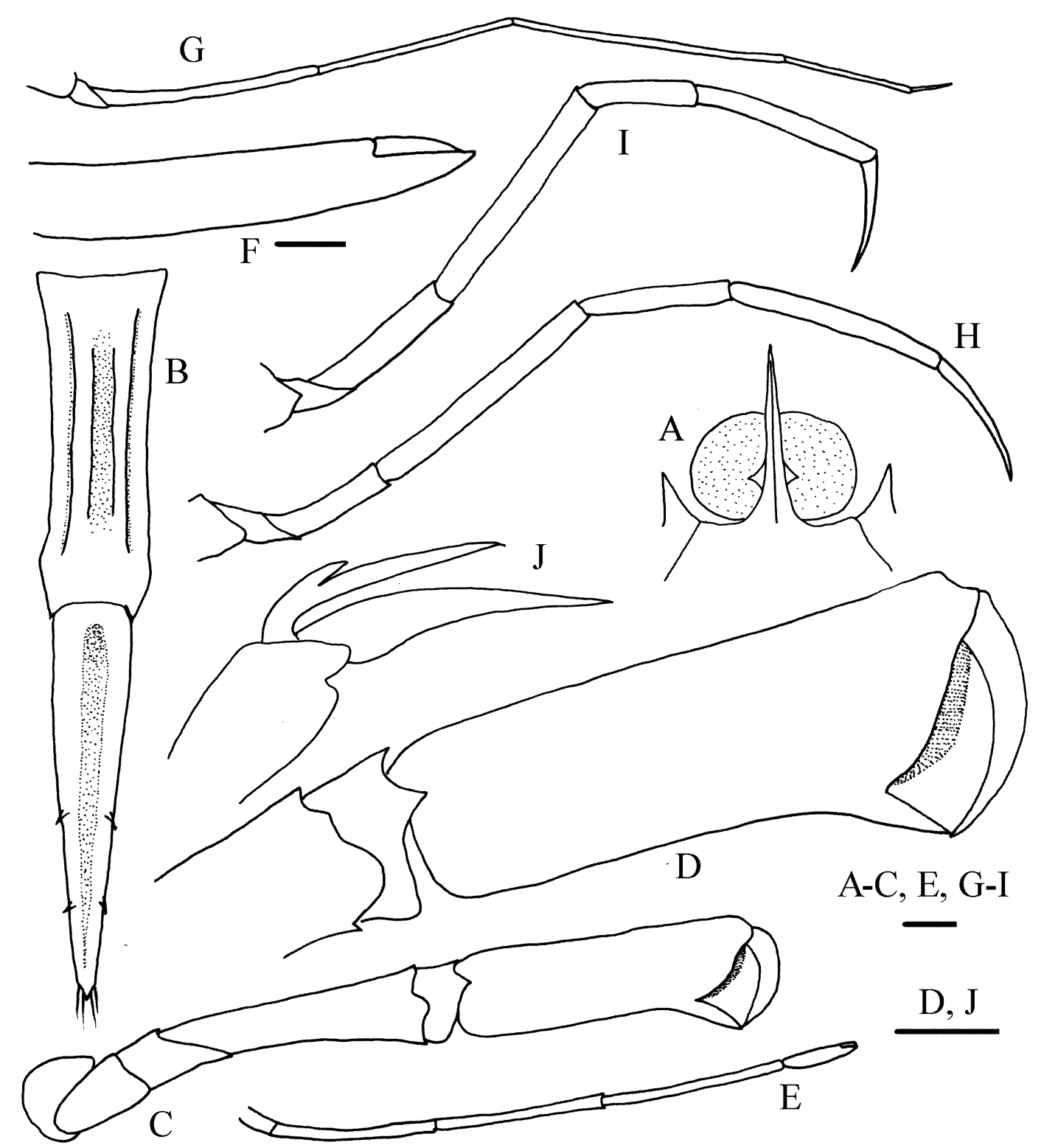

FIGURE 2. Neocrangon orientalis sp. nov. A-I, holotype female (cl $7.71 \mathrm{~mm})$, MBM228966; J, paratype male, MBM228968. A. rostrum and eyes, dorsal view; B. sixth pleomere and telson, dorsal view; C. first pereiopod, ventral view; D. palm of first pereiopod, ventral view; E. second pereiopod, ventral view; F. chela of second pereiopod, ventral view; G. third pereiopod, lateral view; H. fourth pereiopod, lateral view; I. fifth pereiopod, lateral view; J. second male pleopod, ventral view. Scale bars: $1 \mathrm{~mm}(\mathrm{~A}-\mathrm{E}, \mathrm{G}-\mathrm{J}) ; 0.2 \mathrm{~mm}(\mathrm{~F})$.

Remarks. The new species closely resembles Neocrangon resima (Rathbun, 1902) in the situations of the dorsal teeth, smooth tergites of the first five pleomeres, and the long rostrum overreaching anterior margin of the cornea. It differs from $N$. resima by the following characters: 1) the rostrum in the new species arms with faint dorsal carina and cute anterior apex, and distinctly exceeds the end of the cornea (vs. the rostrum in $N$. resima arms with pronounced dorsal sulcus and blunt apex and varies in length); 2) the antennal scale in the new species is $0.94(0.89-0.96)$ times as carapace length and is about 4.13 (3.98-4.27) times as long as broad (vs. the antennal scale in $N$. resima is four fifths of the carapace length, and 3.5 times as long as broad); 3) the posteroventral spine of the pleuron of fourth pleomere is absent, the posterolateral spine on the fifth is present (vs. the fourth pleuron in N. resima arms with minute posteroventral spine, 
the fifth pleuron has posterolateral point); 4) the first and second pleomeres have smooth posterior portions (vs. the posterior portions of the first and second pleomeres in N. resima elevate and are preceded by broad, shallow transverse sulci).

Including the new species, there have been five species in the genus Neocrangon Zarenkov, 1965. The species can be distinguished by the following key.

\section{Key to the species of Neocrangon Zarenkov, 1965}

1. Eyes very large, diameter more than 0.3 times of carapace length .............................. abyssorum (Rathbun, 1902) (northern Pacific from southern California to Pacific coast of Hokkaido, Japan; 887-4000 meters)

Eyes moderate in size, diameter less than 0.3 times of carapace length.......................................................... 2

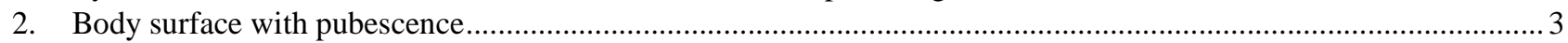

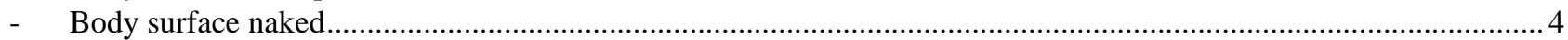

3. Distance between anterior dorsomedian spine of carapace and tip of rostrum more than twice of distance between anterior dorsomedian spine and posterior dorsomedian spine..................................... . communis (Rathbun, 1899)

(Berling Sea to San Diego, California; 16-565 meters)

- Anterior dorsomedian spine situated at about middle from posterior dorsomedian spine to tip of rostrum N. joloensis (De Man, 1929) (off Jolo Island, Philippines)

4. Rostrum with pronounced dorsal sulcus, apex blunt; pleuron of fourth pleomere with posterolateral spine, pleuron of fifth with posterolateral angle pointed.... N. resima (Rathbun, 1902)

(From off San Francisco, California, to San Domingo Point, Lower California; at depths of 27-487 meters)

- $\quad$ Rostrum with faint dorsal carina, apex acute; pleuron of fourth pleomere without posterolateral spine, fifth pleuron with posterolateral spine. $N$. orientalis sp. nov.

\section{Acknowledgements}

This study was supported by the National Scientific Fundation of China (No. 40676088) and the Knowledge Innovation Program of the Chinese Academy of Sciences (IOCAS No. O72715). We thank Drs. T.-Y. Chan (Taiwan Ocean University) and T. Komai (Natural History Museum and Institute of Chiba) for kindly help to copy some related references.

\section{References}

De Man, J.G. (1929) Papers from Dr. Th. Mortensen's Pacific Expedition 1914-1916. I. On a small collection of Decapoda, one of which, a Crangon, caught by the Danish Pacific Expedition at the Jolo Islands, is new to science. Videnskabelige Meddelelser fra Dansk naturhistorisk Forening i Köbenhavn, 87, 105-134, 9 figs.

Fabricius, J.C. (1758) Supplementatione Entomologiae Systematicae. Hafniae: Proft et Storch, ii, 572 pp.

Haworth, A.H. (1825) A new Binary Arrangement of the Macrurous Crustacea. Philosophical Magazine and Journal, $65,183,184$.

Kuris, A.M. \& Carlton, J.T. (1977) Description of a new species, Crangon handi, and a new genus, Lissocrangon, of crangonid shrimps (Crustacea: Caridea) from the California coast, with notes on adaptation in body shape and coloration. Biological Bulletin of the Marine Biological Laboratory, Woods hole, 153(3), 540-559.

Rathbun, M.J. (1899) The fur seals and Fur-Seal Islands of the North Pacific Ocean, Pt. III, 555-558.

Rathbun, M.J. (1902) Descriptions of new decapod Crustaceans from the west Coast of North America. Proceedings of the United States National Museum, 24(1272), 885-905.

Squires, H.J. \& Figueira, A.J.G. (1974) Shrimps and shrimps-like anomurans (Crustacea, Decapoda) from southeastern Alaska and Prince William Sound. National Museum of Canada Publications in Biolobical Oceanography, 6, 1-23.

Wicksten, M.K. (1996) Neocrangon zacae (Chace, 1937) synonymized with N. resima (Rathbun, 1902), and compared with N. communis (Rathbun, 1899) (Decapoda: Caridea: Crangonidae). Proceedings of the Biological Society of Washington, 109(1), 39-43.

Zarenkov, N.A. (1965) Revision of the genus Crangon Fabricius and Sclerocrangon G. O. Sars (Decapoda, Crustacea). Zoologicheskii Zhurnal, 44, 1761-1775. 